\title{
Prof. Dr. Christl Reisenauer: a new Editorial Board Member
}

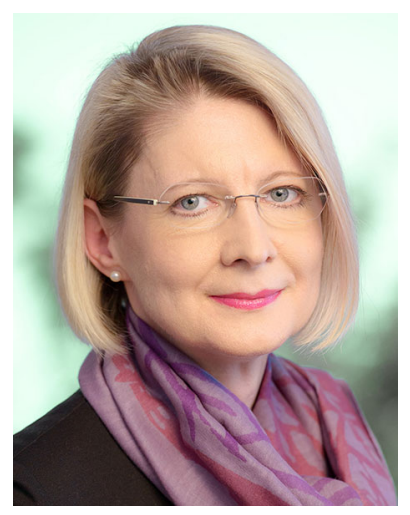

Christl Reisenauer is the Head of the Urogynecological Division of the Department of Obstetrics and Gynecology at University Hospital Tuebingen, Germany. Between 1992 and 1997, she completed her residentship in Obstetrics and Gynecology at the Women's Hospital Stuttgart. Due to her special interest in Urogynecology she started with research activities and continued her clinical activities at the Department of Obstetrics and Gynecology at the University Hospital Tübingen in 2003. She finished her habilitation in 2008 with a project of innovative aspects in the diagnosis and therapy of pelvic floor disorders. She gained a professorship in 2010 in Obstetrics and Gynecology at the University of Tuebingen.

Her research activities are macroscopical anatomy of the pelvic floor, histomorphology of the uterosacral ligament, conservative and operative therapy of urinary incontinence and pelvic organ prolapse and fistulas.

She is a reviewer for leading journals in the field of Urogynecology, author and co-author of numerous publications within the field of Urogynecology and has received several awards for her research activities.

She is the Past-President of the German Urogynecological Association, the Vice-President of the German Continence Society and a member of the Board of the German Society of Obstetrics and Gynecology. 